\title{
Simultaneous monitoring of electrical capacitance and water uptake activity of plant root system
}

\author{
Imre Cseresnyés*, Tünde Takács*, Anna Füzy, and Kálmán Rajkai \\ Institute for Soil Sciences and Agricultural Chemistry, Centre for Agricultural Research, Hungarian Academy of Sciences, \\ H-1022 Budapest, Herman Ottó út 15., Hungary \\ Received May 18, 2014; accepted September 17, 2014
}

\begin{abstract}
A b s t r a c t. Pot experiments were designed to test the applicability of root electrical capacitance measurement for in situ monitoring of root water uptake activity by growing cucumber and bean cultivars in a growth chamber. Half of the plants were inoculated with Funneliformis mosseae arbuscular mycorrhizal fungi, while the other half served as non-infected controls. Root electrical capacitance and daily transpiration were monitored during the whole plant ontogeny. Phenology-dependent changes of daily transpiration (related to root water uptake) and root electrical capacitance proved to be similar as they showed upward trends from seedling emergence to the beginning of flowering stage, and thereafter decreased continuously during fruit setting. A few days after arbuscular mycorrhizal fungi-colonization, daily transpiration and root electrical capacitance of infected plants became significantly higher than those of non-infected counterparts, and the relative increment of the measured parameters was greater for the more highly mycorrhizal-dependent bean cultivar compared to that of cucumber. Arbuscular mycorrhizal fungi colonization caused 29 and $69 \%$ relative increment in shoot dry mass for cucumbers and beans, respectively. Mycorrhization resulted in $37 \%$ increase in root dry mass for beans, but no significant difference was observed for cucumbers. Results indicate the potential of root electrical capacitance measurements for monitoring the changes and differences of root water uptake rate.
\end{abstract}

K e y w o r d s: mycorrhiza, phenology, root electrical capacitance, transpiration, water uptake

\section{INTRODUCTION}

Water and mineral nutrition uptake are the key functions of plant roots. Reliable data on the growth and activity of the root system are essential for the recognition of many plant phenomena related to root development, and thus are needed for various plant physiology and agricultural studies. Destructive root investigation methods are inhe-

*Corresponding author e-mail: cseresnyes.imre@agrar.mta.hu rently unsuitable for in situ monitoring of root growth and function. The applicability of non-destructive techniques is also strongly limited in many cases, as they give a weak resolution of root structure (chiefly to root hairs), producing uncertain or no data on the functional root surface area (Cao et al., 2010; Čermák et al., 2006).

Electrical capacitance (EC) measurement in a plant-soil system can provide a rapid in situ assessment of root status without damage to the plant. This method was developed by Chloupek (1972) using several crop species. By inserting an electrode at the plant stem and another one into the soil, and connecting them by a capacitance meter (LCRbridge), root EC proved to be directly correlated with root dry mass and root surface area. According to Dalton (1995) conceptual model, xylem and phloem sap in root forms a low resistance electrical conduit separated from a low resistance external soil or nutrient solution by isolating root membranes (Fig. 1). Thus the polarised membrane plays the role of a dielectric in a capacitor having a capacitance proportional to the charge stored on the membrane surfaces. Rajkai et al. (2005) recommended a two-dielectric (series-connected root and soil dielectric) capacitor model, where the capacitive character of the soil solution was also considered. Edaphic factors having influence on the accuracy of EC measurements (ie water saturation, soil texture and salinity, electrode placement) were investigated as well (Dalton, 1995; Ozier-Lafontaine and Bajazet, 2005).

Alternating current flows between the root system and soil only through electrically conducting water and ion absorption zones (and not through non-absorbing surfaces such as those covered by impermeable suberin) proportionally to the permeability of root to water (Čermák et al., 2006). Crops were observed to show characteristic

(C) 2014 Institute of Agrophysics, Polish Academy of Sciences 


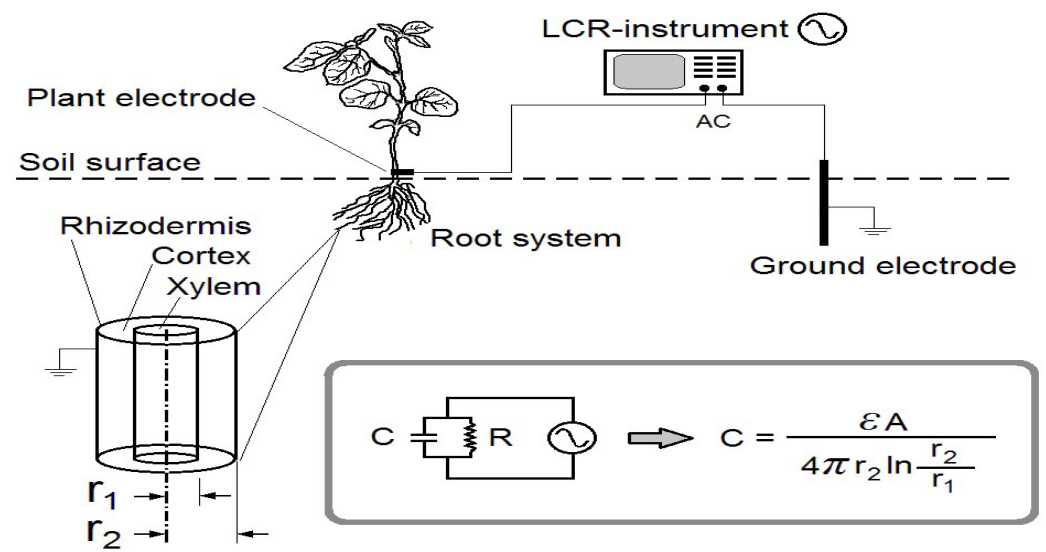

Fig. 1. Principle of electrical capacitance measurement in a plant-soil system, according to Dalton (1995) and Ellis et al. (2013).

changes in the root/shoot ratio during their ontogeny, as well as to produce varietal differences in root characteristics, water extraction and water use (Siddique et al., 1990). As root conductivity and permeability are reliable indicators for water uptake activity and absorptive root surface area (Aston and Lawlor, 1979; Aubrecht et al., 2006), we hypothesised that phenological changes and differences in root water uptake (measured indirectly through the transpiration water loss) could be monitored by EC measurement carried out repeatedly during plant ontogeny. Since arbuscular mycorrhizal fungal (AMF) colonization is known to alter root morphology, conductivity and water uptake capacity, and thus subsequently electrical root properties (Augé, 2001; Cseresnyés et al., 2013b), AMF-infected and nonAMF plants were also used for the experiments.

\section{MATERIALS AND METHODS}

At experiment day 1, germinated cucumber (Cucumis sativus L. cv. 'Perez-F1') and bean (Phaseolus vulgaris L. cv. 'Goldrush') seeds were planted into 3.751 pots containing $3.3 \mathrm{~kg}$ of sterile (free of infective AMF propagules) pumice medium with $0.6-1 \mathrm{~mm}$ particle size, $\mathrm{pH}$ of 6.5 , $0.94 \mathrm{~g} \mathrm{~cm}^{-3}$ bulk density and $0.26 \mathrm{~cm}^{3} \mathrm{~cm}^{-3}$ water content at field capacity. Two seeds were deposited in each pot and after emergence thinned to one for obtaining uniform plant populations. Half of the 30-30 replicates of cucumber (C) and bean $(\mathrm{B})$ plants $[\mathrm{C}(+)$ and $\mathrm{B}(+)]$ received $10 \mathrm{~g}$ of $\mathrm{AMF}$ inoculum in the form of pumice medium and root cuttings of white clover (Trifolium repens L.) host plant colonised by Funneliformis mosseae (Schüssler and Walker; syn. Glomus mosseae Nicholson and Gerdeman), while the other 15-15 plants $[\mathrm{C}(-)$ and $\mathrm{B}(-)]$ served as controls. The inoculum was applied as a thin layer in $5 \mathrm{~cm}$ depth below the seedlings in the pots. Plants were maintained randomly in a growth chamber $\left(26 / 18^{\circ} \mathrm{C}\right.$ and $16 / 8 \mathrm{~h}$ for day/night and $300 \mu \mathrm{mol} \mathrm{m} \mathrm{m}^{-2} \mathrm{~s}^{-1}$ photon flux density) with changing their places daily to avoid position effect. Pots were daily weighed $( \pm 1 \mathrm{~g})$ and irrigated with tap water to field capacity by placing them on an electronic balance in order to measure the water loss by evapotranspiration.
Optimal plant nutritional status was kept up by weekly irrigation with modified Hoagland's solution (with only $10 \%$ $\mathrm{KH}_{2} \mathrm{PO}_{4}$ ). To obtain bare pumice evaporation, extra pots (without plants) were set up and treated the same way as the pots with plants. Plant transpiration was estimated by subtracting pumice evaporation from evapotranspiration derived from the planted pots. Calculated daily transpiration (DT) values were regarded as daily root water uptake (Lai and Katul, 2000; Nomiyama et al., 2013), as biomass increment could be ignored for relative comparison of the results (Yang et al., 1990). Water uptake was expressed in the form of 5-day moving average of daily transpiration (DT) data.

Root EC was measured weekly during plant ontogeny (from exp. day 15 to fruit setting) with a GW-8101G precision LCR instrument (GW Instek Co., Ltd., Taiwan) in a parallel equivalent circuit at $1 \mathrm{kHz}$ frequency with $1 \mathrm{~V}$ terminal voltage. One terminal of the instrument was connected to the plant stem with a spring tension clamp fixed at $15 \mathrm{~mm}$ above the substrate level and a second one earthed by a stainless steel rod (6 mm ID, $15 \mathrm{~cm}$ long) inserted to a depth of $10 \mathrm{~cm}$ into the substrate $5 \mathrm{~cm}$ away from stem base. Electrocardiograph paste was smeared around the stem to keep up electrical contact (Rajkai et al., 2005). Each EC measurement was carried out after the application of Hoagland solution and irrigation to field capacity in order to ensure the optimal and equal water status and the same ionic content in the planting medium.

After the last EC measurement (on exp. day 64 and 50 for cucumbers and beans, respectively), plants were harvested and the root systems were washed thoroughly off the substrate. The intact root systems were weighed and a subsample of roots, consisting primarily of randomly selected fine roots, was taken for determination of AMF root colonization. Both the shoots and the remainders of roots were oven-dried $\left(70^{\circ} \mathrm{C}, 72 \mathrm{~h}\right)$ and reweighed. AMF root colonization was investigated after cleaning and staining the separated root sub-samples with lactic acid-aniline blue (Phillips and Hayman, 1970). AMF infection was quantified 
by using an Olympus B71 type stereoscopic dissecting microscope (40-100X). The intensity (M\%) of colonization was estimated by observing 30 pieces of $1-\mathrm{cm}$-long fine root segments. Extra groups of $\mathrm{C}(+)$ and $\mathrm{B}(+)$ plants were grown and several of them were destructively sampled weekly in order to follow the temporal development of AMF colonization.

Statistical evaluation was performed by using Statistica software (ver. 9., StatSoft Inc., USA). Unpaired t test was used to compare means of data groups in relation to AMF. Nonparametric Welch test was applied in cases when the SDs of the compared groups (F test) were not identical. Correlation between EC and DT values was analysed by simple regression method. Statistical significance was assessed at $\mathrm{p}<0.05$ in each case.

\section{RESULTS AND DISCUSSION}

Our results show characteristic temporal changes in DT derived from irrigation water amount used for cucumber and bean plants during their ontogeny (Fig. 2a). The 5-day moving average of DT increased continuously from seedling emergence to flowering stage and thereafter decreased during the fruit setting. Culmination zones of curves appeared on experiment day 35-39 and 31-35 for cucumbers and beans, respectively, clearly corresponding with experiment day 38 (cucumber) and 33 (bean), when flowers were emerged at $50 \%$ of plants (beginning of flowering). Relative decline in DT values during fruit setting proved to be more pronounced in bean compared to cucumber, presumably due to the more deterministic growing characters of the bean cultivar. DT - and root water uptake consequently - seemed to be about 2 to 4 fold higher for cucumber than for beans, depending on their phenology stage. AMF had an obvious effect on root water uptake and transpiration levels in the case of both vegetable crops. Approximately from exp. day $22-24, \mathrm{C}(+)$ and $\mathrm{B}(+)$ plants showed perceptibly higher DT as opposed to their $\mathrm{C}(-)$ and $\mathrm{B}(-)$ counterparts, and the disparity was maintained in the remaining part of plant ontogeny.

The magnitude of root EC was observed to undergo similar temporal changes to those of the DT (Fig. 2b). EC values had an upward trend during the vegetative stage of plant development, culminated at the flowering stage then reduced continuously through the fruit setting. The peak values of EC occurred on experiment day 43 (cucumber) and 36 (bean), irrespective of AMF. Cucumbers expressed 1.5 to 3 fold higher EC than was detected for beans. The effect of AMF on root electrical properties was clearly reflected by the EC monitoring: from experiment day 29 onwards, $\mathrm{C}(+)$ and $\mathrm{B}(+)$ plants tended to have significantly $(\mathrm{p}<0.05)$ higher signal intensity in $\mathrm{EC}$ than was obtained from their non-infected $\mathrm{C}(-)$ and $\mathrm{B}(-)$ controls. Regression analyses showed positive linear correlation $(\mathrm{p}<0.05)$ between EC (in $\mathrm{nF}$ ) and DT (in $\mathrm{ml}$ ) with the equation of: a

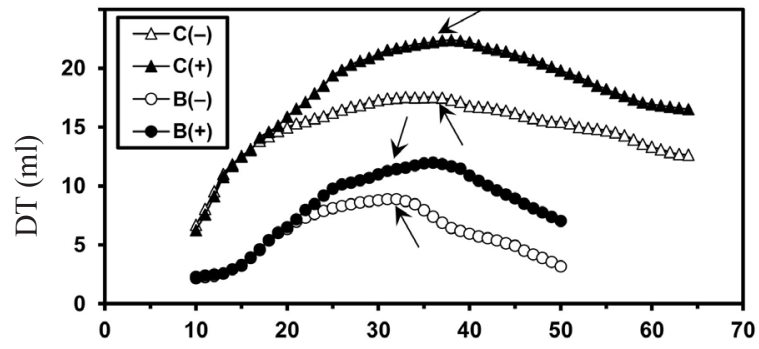

b

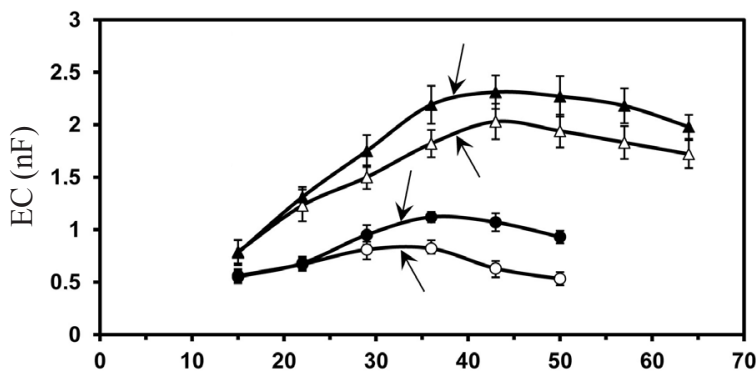

C

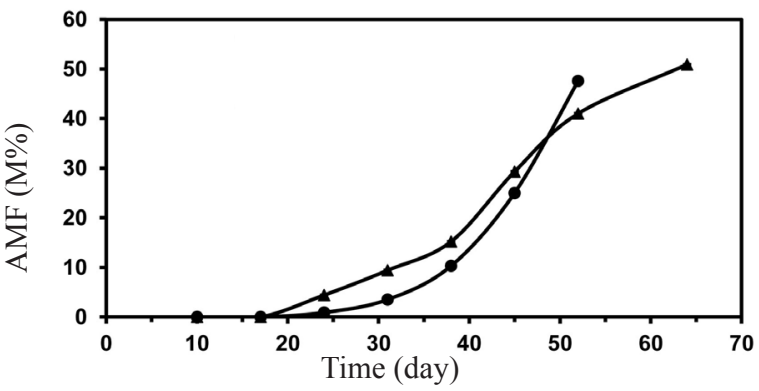

Fig. 2. Changes in: a - daily transpiration ( $\mathrm{ml}, 5$-day moving average), $b$ - signal intensity in root electrical capacitance (EC; $n F)$, and $\mathrm{c}$ - intensity of AMF-colonization (M\%) related to growth time in AMF-colonized (+) and non-AMF (-) cucumber (C) and bean (B) plants. Arrows show the beginning of flowering, vertical bars indicate standard deviations.

$$
\mathrm{EC}=0.107 \mathrm{DT}+0.079(\mathrm{r}=0.768)
$$

for cucumbers and

$$
\mathrm{EC}=0.063 \mathrm{DT}+0.329(\mathrm{r}=0.896)
$$

for beans.

Regularly repeated microscopic investigation of AMF-infected root systems revealed that the initial stage of fungal colonization fell on experiment day 18-23 in general. Thereafter the degree of colonization increased steadily up to $\mathrm{M}=50.9$ and $47.6 \%$ intensity estimated for $\mathrm{C}(+)$ and $\mathrm{B}(+)$ plants, respectively, at the end of the experiment (Fig. 2c).

Mycorrhizal colonization exerted a significant influence on biomass production of both crop species (Fig. 3). Post-harvest biomass measurement showed higher shoot dry mass at AMF-plants compared with the non-infected ones. 29 and $69 \%$ relative increments in shoot dry mass 


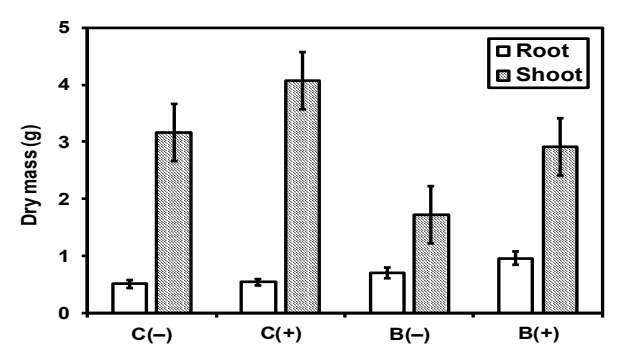

Fig. 3. Root and shoot dry mass (g) of AMF-colonized $(+)$ and non-AMF (-) cucumber (C) and bean (B) plants. Explanations as in Fig. 2.

caused by AMF were calculated for cucumbers and beans, respectively. Considering root growth, the effect of fungal symbiosis proved to be significant only for beans, in which $37 \%$ difference in root dry mass was observed, as opposed to cucumbers where AMF infection had only an insignificant effect on root development.

The initially upward tendency of root water uptake and thereafter its decline with plant maturity were supported by the observations of various studies. Investigation of several crop plants, including cucumber, maize, sorghum, soybean, sunflower and wheat revealed that the transpiration rate and the water and ion uptake activity decreased significantly from the physiologically active stages (vegetative and flowering) to grain-filling and maturity stages (Fu et al., 2002; Novák and Vidovič, 2003). Both the relative proportion and the uptake activity of the highly absorptive, apical young root segments decreased through plant maturity (with concurrently increasing ratio of old roots mainly responsible for transport), resulting in the continuously reducing water uptake of the whole root system (Gao et al., 1998; Lai and Katul, 2000). Considerable reduction in transpiration rate per leaf surface area was also observed in crop plants during the late generative phase of ontogeny (Medrano et al., 2005; Yang et al., 1990).

In our study, colonization of Funneliformis mosseae strain that took place between experiment day 18 and 23 produced higher root water uptake in infected plants within a few days, and contributed to higher biomass production after all. Various effects provoked by the infection of $F$. mosseae or other AMF species in different host plants are widely documented in literature: studies reported on altered root architecture, increased photosynthetic rate, transpiration rate, stomatal and root conductance, as well as enhanced total plant growth and water and nutrient uptake caused by the endomycorrhizal symbiosis (Augé, 2001). Significantly positive effect of AMF on root EC values, as a consequence of the increased root-soil interface, was formerly shown in maize cultivars in pot experiments (Cseresnyés et al., 2013b). The AMF-induced relative increment not only in total plant biomass but also in root EC proved to be higher in bean than in cucumber ( 75 and $15 \%$, respectively, for the last EC measurement), in relation to the higher degree of mycorrhizal dependency generally observed in legumes (Muleta, 2010).

Factual value of root water uptake intensity (in a volume per time unit) is difficult to calculate directly from the measured root EC, even if the mathematical relationship between root EC and water uptake intensity was previously determined by a calibration for given experimental circumstances. Root tissues undergo characteristic physicochemical changes during plant ontogeny, thus the continuously changing current path and root dielectric properties ( $e g$ relative permittivity) leads to an alteration in the computed parameters of the applied regression equation (Cseresnyés et al., 2013a; Dalton, 1995; Ellis et al., 2013). Apart from this limitation, our findings indicate the potential of root EC measurement for in situ monitoring of phenology-dependent changes of plant transpiration and, subsequently, water uptake activity. The method also offers a good opportunity for relative comparison of root water uptake rates, as well as for discerning plant groups subjected to different environmental conditions affecting root or rhizosphere activity. It is important to emphasize that measurement data are comparable only among plants of the same species, grown in the same substrate at the same moisture level in the same time frame (Chloupek et al., 2010). Due to its versatile adaptability, EC measurement can be reliably applicable in various fields of basic and applied plant physiology, ecopysiological and agricultural researches, substituting at least partially the intrusive and labour intensive techniques (Aubrecht et al., 2006; Cao et al., 2010; Cseresnyés et al., 2012, 2013a,b; Svačina et al., 2014).

\section{CONCLUSIONS}

1. The results clearly show that electrical capacitance measurement is a promising and useful technique for in situ monitoring of phenology-dependent changes in root water uptake activity in constant conditions (ie soil type, moisture status and ionic content).

2 . Both root water uptake and root electrical capacitance increased from seedling emergence to the beginning of flowering, then decreased during fruit setting. Arbuscular mycorrhizal fungal infection induced significant increases in these variables a few days after colonization.

3. The electrical capacitance method has a capability to discern plant groups subjected to different environmental conditions influencing root development and activity. Some functional aspects of mycorrhizal colonization can be simply detected in this manner. The degree of mycorrhizal dependency can be also estimated on the basis of electrical capacitance values.

4. The electrical capacitance measurement should be regarded as a versatile test method with potential applicability in various fields of plant physiology and agricultural researches. 


\section{REFERENCES}

Aston M.J. and Lawlor D.W., 1979. The relationship between transpiration, root water uptake and leaf water potential. J. Exp. Botany, 114, 169-181.

Aubrecht L., Staněk Z., and Koller J., 2006. Electrical measurement of the absorption surfaces of tree roots by the earth impedance methods: 1. Theory. Tree Physiol., 26, 1105-1112.

Augé R.M., 2001. Water relations, drought and vesicular-arbuscular mycorrhizal symbiosis. Mycorrhiza, 11, 3-42.

Cao Y., Repo T., Silvennionen R., Lehto T., and Pelkonen P., 2010. An appraisal of the electrical resistance method for assessing root surface area. J. Exp. Botany, 61, 2491-2497.

Čermák J., Ulrich R., Staněk Z., Koller J., and Aubrecht L., 2006. Electrical measurement of tree root absorbing surfaces by the earth impedance method: 2 . Verification based on allometric relationships and root severing experiments. Tree Physiol., 26, 1113-1121.

Chloupek O., 1972. The relationship between electric capacitance and some other parameters of plant roots. Biologia Plantarum, 14, 227-230.

Chloupek O., Dostál V., Středa T., Psota V., and Dvořáčková O., 2010. Drought tolerance of barley varieties in relation to their root system size. Plant Breeding, 129, 630-636.

Cseresnyés I., Fekete G., Végh R.K., Székács A., Mörtl M., and Rajkai K., 2012. Monitoring of herbicide effect in maize based on electrical measurements. Int. Agrophys., 26, 243-247.

Cseresnyés I., Rajkai K., and Vozáry E., 2013a. Role of phase angle measurement in electrical impedance spectroscopy. Int. Agrophys., 27, 377-383.

Cseresnyés I., Takács T., Végh R.K., Anton A., and Rajkai K., 2013b. Electrical impedance and capacitance method: a new approach for detection of functional aspects of arbuscular mycorrhizal colonization in maize. Eur. J. Soil Biol., 54, 25-31.

Dalton F.N., 1995. In-situ root extent measurements by electrical capacitance methods. Plant Soil, 173, 157-165.

Ellis T., Murray W., and Kavalieris L., 2013. Electrical capacitance of bean (Vicia faba) root systems was related to tissue density - a test for the Dalton Model. Plant Soil, 366, $575-584$.
Fu S., Cheng W., and Susfalk R., 2002. Rhizosphere respiration varies with plant species and phenology: a greenhouse pot experiment. Plant Soil, 239, 133-140.

Gao S., Pan W.L., and Koenig R.T., 1998. Integrated root system age in relation to plant nutrient uptake activity. Agronomy J., 90, 505-510.

Lai C-T. and Katul G., 2000. The dynamic role of root water-uptake in coupling potential to actual transpiration. Advances Water Res., 23, 427-439.

Medrano E., Lorenzo P., Sánchez-Guerrero M.C., and Montero J.I., 2005. Evaluation and modelling of greenhouse cucumber crop transpiration under high and low radiation conditions. Scientia Horticulturae, 105, 163-175.

Muleta D., 2010. Legume responses to arbuscular mycorrhizal fungi inoculation in sustainable agriculture. In: Inoculation Microbes for Legume Improvement (Eds M.S Khan, A. Zaidi, J. Musarrat). Springer Press, Wien, Austria.

Nomiyama R., Yasutake D., Sago Y., and Kitano M., 2013. Transpiration integrated model for root ion absorption under salinized condition. Biologia, 68, 1113-1117.

Novák V. and Vidovič J., 2003. Transpiration and nutrient uptake dynamics in maize (Zea mays L.). Ecol. Model., 166, 99-107.

Ozier-Lafontaine H. and Bajazet T., 2005. Analysis of root growth by impedance spectroscopy (EIS). Plant Soil, 277, 299-313.

Phillips J.M. and Hayman D.S., 1970. Improved procedures for clearing roots and staining parasitic and vesiculararbuscular mycorrhizal fungi for rapid assessment of infection. Trans. British Mycological Soc., 55, 157-160.

Rajkai K., Végh R.K., and Nacsa T., 2005. Electrical capacitance of roots in relation to plant electrodes, measuring frequency and root media. Acta Agron. Hung., 53, 197-210.

SiddiqueK.H.M.,BelfordR.K., andTennantD.,1990.Root:shoot ratios of old and modern, tall and semi-dwarf wheats inaMediterranean environment. Plant Soil, 121, 89-98.

Svačina P., Středa T., and Chloupek O., 2014. Uncommon selection by root system size increases barley yield. Agron. Sustain. Dev., 34, 545-551.

Yang X., Short T.H., Fox R.D., and Bauerle W.L., 1990. Transpiration, leaf temperature and stomatal resistance of a greenhouse cucumber crop. Agric. Forest Meteorol., 51, 197-209. 